\title{
Short- and long-range energy strategies for Japan and the world after the Fukushima nuclear accident
}

\author{
K. Muraoka, ${ }^{\mathrm{a},{ }^{* b}}$ F. Wagner ${ }^{\mathrm{C}}$ Y. Yamagata ${ }^{\mathrm{d}}$ and A. J. H. Donné \\ ${ }^{a}$ Plazwire Co., Ltd, \\ 2-3-54 Higashi-naka, Fukuoka 812-0892, Japan \\ ${ }^{b}$ Kyushu University (Emeritus), Japan \\ ${ }^{c}$ Max-Planck-Institut für Plasmaphysik, \\ Wendelsteinstraße 1, D-17491 Greifswald, Germany \\ ${ }^{d}$ Kyushu University, \\ 6-1 Kasuga-koen, Kasuga, Fukuoka 816-8580, Japan \\ e EUROfusion, \\ Boltzmannstraße 2, D-85748 Garching bei München, Germany \\ E-mail: k-muraoka@plazwire.co.jp
}

\begin{abstract}
The accident at the Fukushima Dai-ichi nuclear power station in 2011 has caused profound effects on energy policies in Japan and worldwide. This is particularly because it occurred at the time of the growing awareness of global warming forcing measures towards decarbonised energy production, namely the use of fossil fuels has to be drastically reduced from the present level of more than $80 \%$ by 2050 . A dilemma has now emerged because nuclear power, a $\mathrm{CO}_{2}$-free technology with proven large-scale energy production capability, lost confidence in many societies, especially in Japan and Germany. As a consequence, there is a world-wide effort now to expand renewable energies (REs), specifically photo-voltaic (PV) and wind power. However, the authors conjecture that PV and wind power can provide only up to a $40 \%$ share of the electricity production as long as sufficient storage is not available. Beyond this level, the technological (high grid power) and economic problems (large surplus production) grow. This is the result of the analysis of the growing use of REs in the electricity systems for Germany and Japan. The key element to overcome this situation is to develop suitable energy storage technologies. This is particularly necessary when electricity will become the main energy source because also transportation, process heat and heating, will be supplied by it. Facing the difficulty in replacing all fossil fuels in all countries with different technology standards, a rapid development of carbon capture and storage (CCS) might also be necessary. Therefore, for the short-range strategy up to 2050, all meaningful options have to be developed. For the long-range strategy beyond 2050, new energy sources (such as thermonuclear fusion, solar fuels and nuclear power - if inherently safe concepts will gain credibility of societies again), and large-scale energy storage systems based on novel concepts (such as large-capacity batteries and hydrogen) is required. It is acknowledged that the prediction of the future is difficult; therefore, the only insurance in this situation is by intensified research into all viable options.
\end{abstract}

KEYWORDS: Analysis and statistical methods, Data processing methods, Simulation methods and programmes, Energy strategy.

\footnotetext{
* Corresponding author.
} 


\section{Contents}

1. Introduction 1

2. The aftermath of the Fukushima nuclear accident 2

3. The need of decarbonized energy production $\quad 2$

4. Short-range energy strategies for Japan and the world 3

4.1 The present Japanese status and a projection to $2050 \quad 4$

$\begin{array}{ll}\text { 4.2 Short-range energy strategies for the world } & 7\end{array}$

4.2.1 Industrialised countries which try to abolish nuclear energy in the near future $\quad 7$

$\begin{array}{ll}\text { 4.2.2 Other industrialized countries which try to keep nuclear power } & 8\end{array}$

4.2.3 Rapidly emerging countries which are accelerating the introduction of nuclear energy to try to meet their rapidly increasing energy consumptions 8

$\begin{array}{lr}\text { 4.3 Energy use through electricity } & 9\end{array}$

5. Long-range energy strategies for Japan and the world 10

$\begin{array}{ll}5.1 \text { New energy sources } & 10\end{array}$

$\begin{array}{ll}\text { 5.1.1 Solar fuels } & 10\end{array}$

$\begin{array}{ll}\text { 5.1.2 Thermonuclear fusion } & 10\end{array}$

$\begin{array}{ll}5.2 \text { Energy storage systems } & 11\end{array}$

$\begin{array}{ll}\text { 5.2.1 Batteries } & 11\end{array}$

5.2.2 Hydrogen 12

$\begin{array}{ll}\text { 6. Summary } & 12\end{array}$

References $\quad 13$

\section{Introduction}

The Fukushima Dai-ichi nuclear accident, triggered by a strong earthquake at 14:46 on 11th March 2011 and subsequent tsunamis, has had a deep impact on energy policies not only in Japan but worldwide. In this paper, the consequences of this accident for the future energy strategies of Japan and world-wide are discussed. This paper has the following structure: Section 2 briefly describes the aftermath of the accident with the resultant public opinion turning heavily against nuclear power. Section 3 describes the necessity of decarbonised energy production by referring to known climate facts. Section 4 offers a projection of energy demand and supply for Japan up to 2050 (the short-range strategy), followed by a brief description of short-range strategies of different countries in the world. Section 5 then discusses the long-range strategy (beyond 2050), to point out the necessity of urgently developing completely new energy sources/storage systems. Finally, a brief summary is presented in Sec. 6 . 


\section{The aftermath of the Fukushima nuclear accident}

Figure 1 shows the three restricted areas, due to the radiation levels after the nuclear accident. The following radiation levels are predicted values 10 years after the accident. Area (1) is 'impossible to live in the near future' because the radiation level will still be above $10 \mathrm{mSv} / \mathrm{y}$; area (2) is 'accessible but not allowed to live' with a few mSv/y; and area (3) is 'planning for living in the near future' with almost $1 \mathrm{mSv} / \mathrm{y}$. The areas and the numbers of evacuees from the three areas as of October 2014 were, respectively, $337 \mathrm{~km}^{2}$ and 24,400 people, $304 \mathrm{~km}^{2}$ and 23,000 people, and $509 \mathrm{~km}^{2}$ and 31,800 people, totaling 1,150 $\mathrm{km}^{2}$ and 79,200 people. In addition to these compulsory evacuees, there are about 30,000 evacuees from outside the restricted areas, who voluntarily left their homes due to concerns for radiation exposure. Although there was no loss

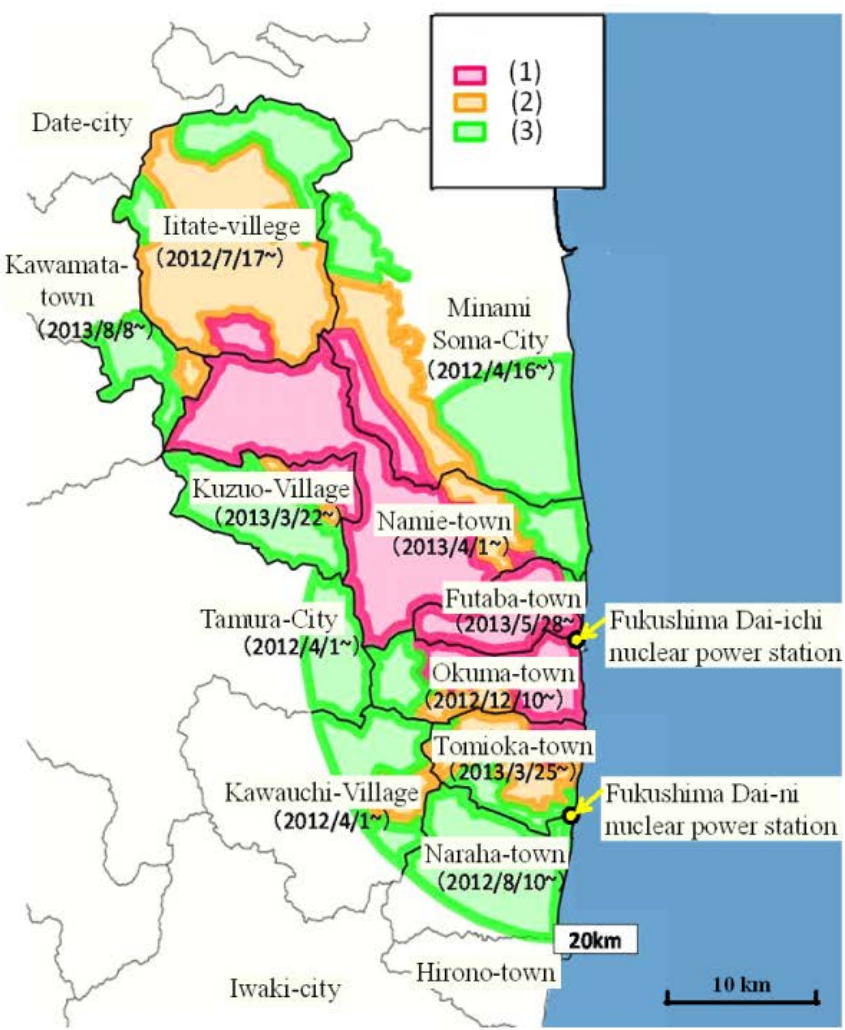

Figure 1 Three restricted areas around the Fukushima Daiichi nuclear power station [1]. of life due to radiation exposure by the accident, there have been 1,900 approved deaths by local governments, mostly elderly, due to stresses during evacuation. These consequences of the accident have caused a strong antinuclear feeling among people in Japan, always $60-70 \%$ disapproving nuclear power. A detailed analysis of the situation around the Fukushima nuclear accident is presented in ref. [2].

\section{The need of decarbonized energy production}

Because basic arguments about the need of decarbonized energy production are well known by now, some illustrative figures together with brief explanations are given.

Global $\mathrm{CO}_{2}$ emissions grow almost exponentially since around 1900. Figure 2 illustrates the $\mathrm{CO}_{2}$ emissions per capita in 2005 [3] plotted against the populations of the various nations considered. The area corresponds to the overall $\mathrm{CO}_{2}$ emission of the respective country. Prominent in this chart are the USA due to a large $\mathrm{CO}_{2}$ emission per capita and China due to its large population. From Fig. 2, one recognises three distinct groups of countries with regard to the $\mathrm{CO}_{2}$ emission per capita, namely USA, Canada and Australia exceeding 20 tons/capita, most industrialized counties having an emission around 10 tons/capita, and developing and emerging countries contributing less than 5 tons/capita . 
These anthropogenic $\mathrm{CO}_{2}$ emissions have resulted in a steady increase of the global average temperature by about 0.7 degrees over the past 100 years. The most apparent effect of this temperature increase is the shrinking Arctic ice caps, as documented in Fig. 3 [4]. It is a realistic threat that the ice cap will completely disappear sometime in the middle of this century, which will reduce the albedo and further accelerate the temperature increase.

Based on these gloomy prospects, the IPCC (Intergovernmental Panel on Climate Change) [5] claims that a necessary reduction of $50 \%$ of the worldwide $\mathrm{CO}_{2}$ emission compared with the present level is required by 2050 in order to limit global warming to less than $2^{\circ} \mathrm{C}$ of the level before the industrial revolution.

Because industrialized countries have so far benefitted most from the use of fossil fuels, they would have to bear the larger share of the burden, probably amounting to a reduction in the use of fossil fuels from presently more than $80 \%$ in their energy portfolio to $10 \%$ by 2050 , while allowing emerging countries to try to meet their increased energy demands partly by increasing their use. Recently, IPCC has cited that industrialized countries have to reduce $\mathrm{CO}_{2}$ emissions by $41 \sim 72 \%$ by 2030 compared with the emission values of 2010 [5].

\section{Short-range energy strategies for Japan and the world}

Presently, Japan and the world have only three options of primary energy sources: fossil fuels, renewable energies (REs) and nuclear energy. Their contributions for Japan were, respectively, $82 \%, 7 \%$, and $11 \%$ in 2010 , and $93 \%, 7 \%$, and $0 \%$ in 2014 , and those for the world were $82 \%$, $14 \%$ and $5 \%$ in 2012. These values clearly illustrate that both Japan and the world rely on fossil fuels for more than $80 \%$, whereas the nuclear energy for Japan before the accident has been exclusively replaced by fossil fuels. REs here are largely biomass and hydroelectricity for both Japan and the world. 
If nuclear energy and its replacement by fossil fuels are not options, the only remaining primary energy source are REs. But as shown later, they also have limitations and drawbacks. In order to discuss and to easily understand and visualize the energy path up to 2050, the authors adopt a methodology which has been introduced by MacKay in his enlightening book [3]. Production and consumption are broken down in energy per person per day and expressed in $\mathrm{kWh} /$ person/day. As an example, Japan consumed $1.43 \times 10^{19}$ Joule/y in 2012 just after the 2011 nuclear accident, which corresponds to $86 \mathrm{kWh} /$ person/day. This value implies that a person in Japan, from new-born to elderly, is constantly consuming $86 \mathrm{kWh} / 24 \mathrm{~h}=3.6 \mathrm{~kW}$. In order to even better understand the consumption of $3.6 \mathrm{~kW}$, we can compare it with the electricity consumption per capita which is generally well understood because the utilities confront us regularly with the electricity bill. A three-person household in Japan consumes 3,600 kWh electricity per year. This corresponds to a per capita consumption of $0.14 \mathrm{~kW}$ (thermal conversion losses included). The comparison of these numbers shows that electricity for private purposes is only a small part of the overall energy consumption though it is generally in the forefront of the public debate.

Finally for later references, the magnitude of $1 \mathrm{kWh} /$ person/day for the population of Japan is obtained as $\left(1 \times 10^{3} \times 1.27 \times 10^{8}\right) / 24=5.3 \times 10^{9}$, namely $5.3 \mathrm{GW}$, which is an electricity output from about 5 large thermal electricity generators.

The distribution of the above value of $86 \mathrm{kWh} /$ person/day for Japan among various sectors is as follows (rounded off to the nearest integral number): $43 \%$ for industry (37 kWh/person/day), $14 \%$ for household (12 kWh/person/day), 20\% for offices/services (17 kWh/person/day) and $23 \%$ for transportation (20 kWh/person/day).

Energy consumptions of several countries in terms of $\mathrm{kWh} /$ person/day for the year 2012 were: France 87, Germany 85, USA 157, China 43, and India 13. European industrialized countries consume about the same amounts as Japan does, while USA, Canada and Australia consume about twice, and China about half of Japan. These facts are consistent with Fig. 2, because fossil fuels supply more than $80 \%$ for all these nations.

\subsection{The present Japanese situation and a projection to 2050}

A conceivable projection of the energy consumption up to 2050 is shown in Fig. 4 with 86 $\mathrm{kWh} /$ person/day for the year 2012 taken as the starting point. It is to be noted that the primary energy consumption of Japan for the year 2012 was $2.08 \times 10^{19} \mathrm{~J} / \mathrm{y}$, which corresponds to 125 $\mathrm{kWh} /$ person/day. This increase of about $50 \%$ is mainly caused by the conversion efficiency from thermal to electrical energies which is about $40 \%$. We nevertheless start with $86 \mathrm{kWh} /$ person/day because firstly thermal power plants have to

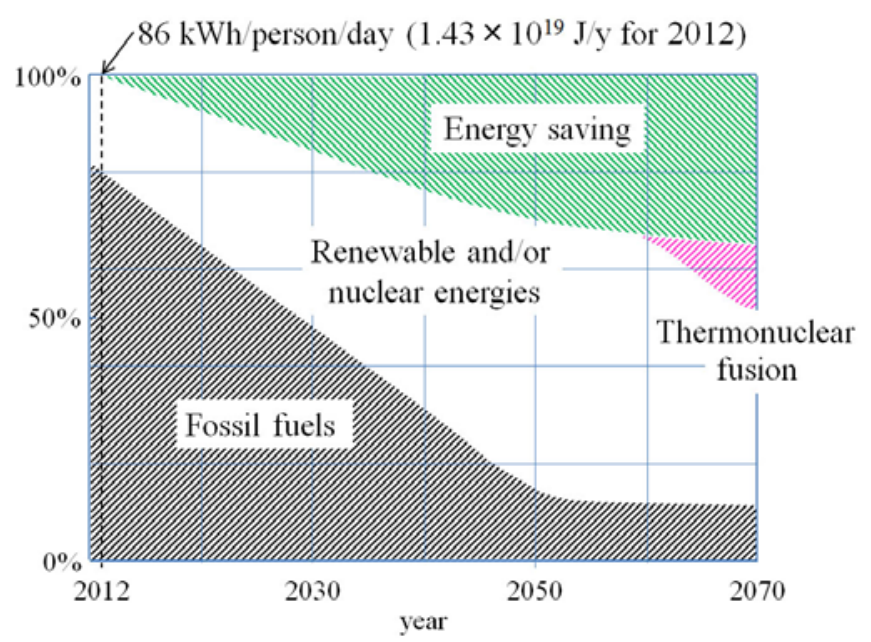

Figure 4 A possible scenario of the Japanese energy consumption to 2050 [6]. "Thermonuclear fusion” is discussed later in the Subsection 5:1-2. 
be almost completely eliminated by 2050 (if nuclear power is disregarded). Secondly, newly emerging primary energy sources, such as PV and wind power, generate electricity directly and do not require energy conversion through a thermal process.

There are many uncertainties in projecting the energy supply and consumption of a nation for several decades into the future. One is the population change (the Japanese population is predicted to decrease by about $30 \%$ by 2050 ), which, however, does not play a role in our per capita based considerations.

Two factors have to be considered for the future energy projection; the first addresses energy saving, and the other the reduction of fossil fuels and their replacement by REs during this period. Regarding energy saving, Japan has already decreased the consumption, which dropped by $5 \%$ from $90 \mathrm{kWh} /$ person/day in 2010 before the accident to the quoted value of 86 $\mathrm{kWh} /$ person/day after it. Because of this decrease, the authors restrict the potential for further reductions to $30 \%$ which is considered as a reasonable target [6]. In deriving this $30 \%$ reduction down to $60 \mathrm{kWh} /$ person/day, a significant reduction in consumption is assumed for industry and transportation by expecting efficiency improvements. However, household and service sectors are assumed to maintain almost their present values, keeping in mind the increased energy needs of a rapidly aging society which will offset efficiency improvements in, e.g., electrical appliances. The resulting distribution after the saving among sectors is as follows: $38 \%$ for industry (23 kWh/person/day), 20\% for household (12 kWh/person/day), 25\% for offices/services (15 kWh/person/day) and 17\% for transportation (10 kWh/person/day). It is assumed that fossil fuels will still contribute with $10 \%$ in 2050, because some portions of fossil fuel-intensive industries, such as steel-making, cement and chemical industries, will be maintained while fossil fuels for electricity production will have to be almost completely eliminated (which may be difficult, given the necessary storage capacity required for its realisation, as discussed later).

These two projections are plotted in Fig. 4 for Japan as two smooth curves, and the middle area shown as white has to be supplied by either REs or nuclear energy, or an appropriate mix of the two. As one sees from Fig. 4, 60\% of the present consumption of $86 \mathrm{kWh} /$ person/day, namely $52 \mathrm{kWh} /$ person/day, has to be replaced by REs and nuclear energy by 2050 .

Next, the potentials of REs and nuclear energy for Japan in 2050 are addressed based on the argument as given in ref. [6]. A brief summary follows:

(1) REs other than PV and wind: Presently, the largest contribution of REs in Japan comes from hydroelectricity, amounting to $3 \mathrm{kWh} /$ person/day. Because most potential sites for hydroelectricity have already been developed, there seems to be no room for further exploitation except for small water mills which would never match the level of $1 \mathrm{kWh} / \mathrm{person} / \mathrm{day}$. The present geothermal energy in Japan, though believed to be one of the biggest geothermal electricity producers in the world, amounts to only $0.1 \mathrm{kWh} /$ person/day. The maximum possible potential in future is estimated to be about $2 \mathrm{kWh} /$ person/day [6]. The use of biomass and waste are limited due to considerations regarding bio-diversity in this over-crowded country and will never match the level of $1 \mathrm{kWh} /$ person/day. Contributions of future wave and tide energies are difficult to estimate at the present primitive stage of their development, but all these sources combined will hardly exceed $5 \mathrm{kWh} /$ person/day in 2050. Therefore, the maximum contribution of these sources in 2050 will amount to maximally $10 \mathrm{kWh} /$ person/day. As a corollary, PV, wind and nuclear energies have to produce at least $42 \mathrm{kWh} /$ person/day. 
(2) PV and wind: The limiting factors for Japan are its small size $\left(380,000 \mathrm{~km}^{2}\right)$ and its large population $\left(1.27 \times 10^{8}\right.$ people). Because $15 \mathrm{~W} / \mathrm{m}^{2}$ is obtainable from PV [6], Japan could meet the target value of $42 \mathrm{kWh} /$ person/day by 2050, if it would devote about $4 \%$ of its land area for solar PV parks. However, one has to bear in mind that only about $15 \%$ of the total area in Japan is flat land, and this area is mostly occupied by houses, factories, offices, roads, and used for agricultural purposes. On the other hand, $2 \mathrm{~W} / \mathrm{m}^{2}$ from onshore and $3 \mathrm{~W} / \mathrm{m}^{2}$ from offshore wind are obtainable under Japanese conditions [6]. Japan could meet the target value of $42 \mathrm{kWh} /$ person/day by 2050, if it would devote about $11 \%$ of its combined land and ocean area for onshore and offshore wind parks.

Next, let us have a closer look at the sort of land and ocean areas Japan could provide for PV and wind parks from now to 2050. Assuming a maximum land area available for PV and onshore wind parks (they can share the same land) of about $1 \%$ of the total land area yields about $10 \mathrm{kWh} /$ person/day. Also, if an ocean area corresponding to $5 \%$ of the land area would be used for offshore wind parks, these would yield $11 \mathrm{kWh} /$ person/day. In total, 23 $\mathrm{kWh} /$ person/day could be supplied by PV and wind parks. This corresponds to about $55 \%$ of the target value of $42 \mathrm{kWh} /$ person/day.

There may be practical constraints to realize the above PV and wind power shares. These are (i) an electricity price increase due to their costly introduction and (ii) their characteristics to provide electricity in an intermittent fashion. Item (i) is discussed in Sec. 4.2.1. quoting the case of Germany with large wind and PV installations, and item (ii) is discussed in Sec. 4.3 in more detail.

(3) Nuclear energy: The largest projection in 2050 may be doubling the value before the Fukushima nuclear accident of $6 \mathrm{kWh} /$ person/day to $12 \mathrm{kWh} /$ person/day by means of replacing old reactors (some have electricity outputs of less than $0.5 \mathrm{GW}$ ) with newer/safer ones having a unit-output of about $1.5 \mathrm{GW}$. The opposite side of the spectrum is no nuclear power at all by 2050 as it has been the position of the previous government in Japan. We will have to wait and see whether inherently safe nuclear power concepts [7] gain support of the society again. This question may also depend on how seriously the society will take global warming in the coming decades.

(4) Possible scenarios for 2050: Based on the estimations derived above, one ends up at the maximum possible value of $23 \mathrm{kWh} /$ person/day from $\mathrm{PV}$ and wind parks plus 12 $\mathrm{kWh} /$ person/day from nuclear energy, which sum up to $35 \mathrm{kWh} /$ person/day. Even this very much optimistic prediction yields less than $42 \mathrm{kWh} /$ person/day, which is our assumed target for sustaining a highly developed society.

(5) Possible steps to meet the target: If the white area of $52 \mathrm{kWh} /$ person/day in 2050 in Fig. 4 is not covered by a combination of PV, wind, other forms of REs plus nuclear energy in the frame of the discussion above, which options might be possible to save the situation for Japan?

There are two obvious possibilities in Fig. 4, namely first to increase energy saving beyond the assumed $30 \%$, and secondly to increase the residual level of fossil fuels above the $10 \%$ assumption. The former would ensure quite drastic changes in the way of living for all average Japanese, and it is a topic to be discussed from political/sociological/philosophical standpoints, which is beyond the scope of this article.

Regarding the latter possibility, one would have to increase the use of fossil fuels without releasing additional $\mathrm{CO}_{2}$ gas into the atmosphere. The well-known solution is to resort to CCS 
technology (Carbon Capture and Storage). However, this technology is still at an initial stage, and requires much investment for further development to commercial application. In addition, the operation of this technology would consume about 30\% of the energy contained in the fuels. Moreover, CCS has also the drawback of possible environmental effects due to leaks of stored $\mathrm{CO}_{2}$, either geologically or in oceans. Above all, even if this option is realized, it may have a limited life-time, because of the limited cavity space of most countries. Also, the $\mathrm{CO}_{2}$ has to be stored as locally as possible to avoid costly transportation over longer distances.

\subsection{Short-range energy strategies for the world}

In spite of the ethical, cultural and economic differences of the nations on earth, most of them share the same challenge as Japan - the necessity of replacing fossil fuels by REs and/or nuclear energy. In the following, let us have a look at different countries from their positions toward nuclear energy.

\subsubsection{Industrialised countries which try to abolish nuclear energy in the near future}

Those countries which plan to abandon nuclear energy include Italy (already abandoned after the Chernobyl accident), Germany, Sweden and Switzerland. As an example, let us take Germany, as it is the country with the largest energy consumption of this group.

The German government decided to abolish nuclear energy by 2022 after having witnessed the Fukushima consequences. This decision has been supported by a large part of the population. Since then, the German government has been seriously pushing policies to reduce the national energy consumption by heavily subsidizing such activities as better insulation for houses and increasing fuel efficiency of cars. Figure 5 plots the following values for Germany from 1990 to 2011, namely the primary energy consumption, the economic growth and the energy intensity. The last value has been decreased by $30 \%$ from 1990 to 2011, and the primary energy consumption dropped by $6 \%$ in this period; it is the political goal to reduce it to $50 \%$ of the 2008 value by 2050 .

In addition, the FIT (feed-in tariff) system was introduced in 2000 to advance REs in Germany. Since then, about $70 \mathrm{GW}$ of wind and PV power have been installed. This built-up has produced severe economic problems for the back-up systems needed to fill low-wind and solar periods because the capacity factors of these systems have strongly dropped. Whereas the nearly doubling of the electricity capacity has sent the spot-market electricity price nearly to the bottom, the electricity price for the consumer has strongly increased. Figure 6 shows an almost linear relationship between electricity prices versus installed REs per capita in 2012 for various 
European countries and the USA, together with the price developments for Germany and Denmark from 1999 to 2012. Of course, the linear relationship of Fig. 6 will not hold up to the $100 \%$ electricity supply case. For this limit, the wind and PV power has still to be increased by a factor of 4-5. The German and the Danish developments clearly demonstrate the high costs by changing the electricity supply system. In addition, it has to be kept in mind that electricity is presently supplying only a quarter of the total energy consumption. As electricity is the primary energy of the future, the costly supply by REs has to be further expanded by a corresponding figure.

\subsubsection{Other industrialized countries which try to keep nuclear power}

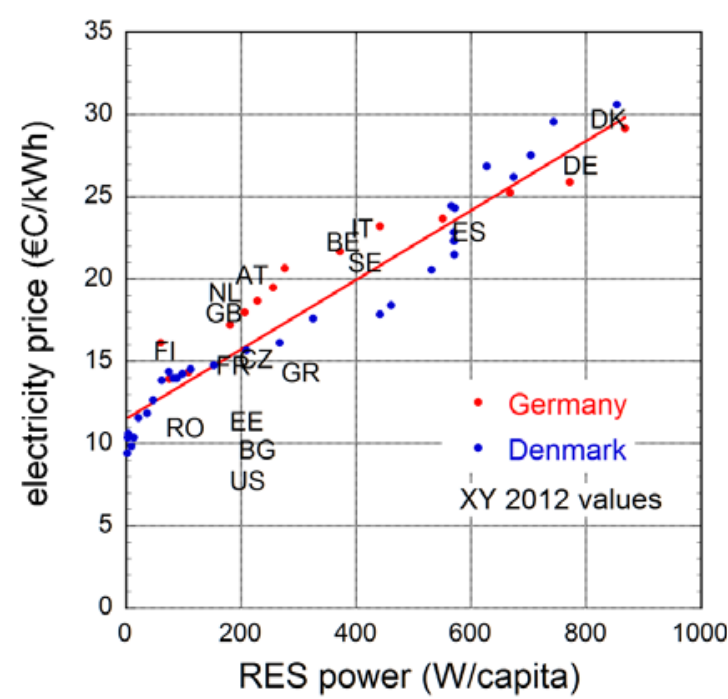

Figure 6 Electricity prices of European countries in 2012, shown together with price increases for Germany and Denmark versus the installed RES power [8].

This group includes USA, France and Britain, which try to keep the nuclear power open at reasonable levels and by tightening up the grip of regulations after the Fukushima nuclear accident. It has to be noted, however, that the Fukushima accident had deep impact on the public conception of nuclear energy also in these countries. For example, in the US $44 \%$ is in favour of the increased use of nuclear power and $49 \%$ opposed [9] and in France, where $75 \%$ of electricity is supplied from nuclear power, $20 \%$ of respondents is in favour of nuclear energy with 50\% supporting of dropping it [10]. Also, high-level radioactive waste management is still in the planning stages in all these countries, while firm decisions have been taken by Finland and Sweden.

\subsubsection{Rapidly emerging countries which are accelerating the introduction of nuclear energy to try to meet their rapidly increasing energy consumptions}

This group includes China and India, together with fast developing countries, such as Vietnam, Turkey and others. The amazing pace of the introduction of nuclear energy in China can be seen from the 2014 power level of $20 \mathrm{GW}$ from 21 reactors to the development plan of $80 \mathrm{GW}$ in 2020 up to $200 \mathrm{GW}$ in 2030, and finally $400 \mathrm{GW}$ in 2050 [11]. Although the Fukushima nuclear accident delayed some of these plans, the government will push the development forward to try to ease some of the severe air pollution caused by burning low-grade coal. The proposed output power of $400 \mathrm{GW}$ in 2050 matches basically the present capacity of the whole world of $388 \mathrm{GW}$ ! Also, China is planning to construct high-level waste repository in the desert of Gobi, to be built around 2040. But there are also voices inside China which point out the dangers due to an earthquake-prone country and the shortage of qualified plant workers/safety inspectors [11].

India presently operates 5.8 GW and has an additional 6.1 GW under construction. It has an ambitious plan to realize $63 \mathrm{GW}$ of nuclear power by 2032, in order to meet the rapidly increasing energy consumption of its growing population. Again, the Fukushima accident has caused public concerns against nuclear power, which may force the government to modify its 
plan. Vietnam, Turkey and other countries have come to, or are in the processes of agreements with Russia, China and other countries for building nuclear power stations.

\subsection{Energy use through electricity}

Figure 7 shows the temporal development of the share of electricity in the final energy consumption for several countries along with the world average, indicating a steady increase up to the present level of about one quarter of the final energy consumption. This ratio can be expected to drastically increase in the coming years because of its versatility to serve all energy related purposes,

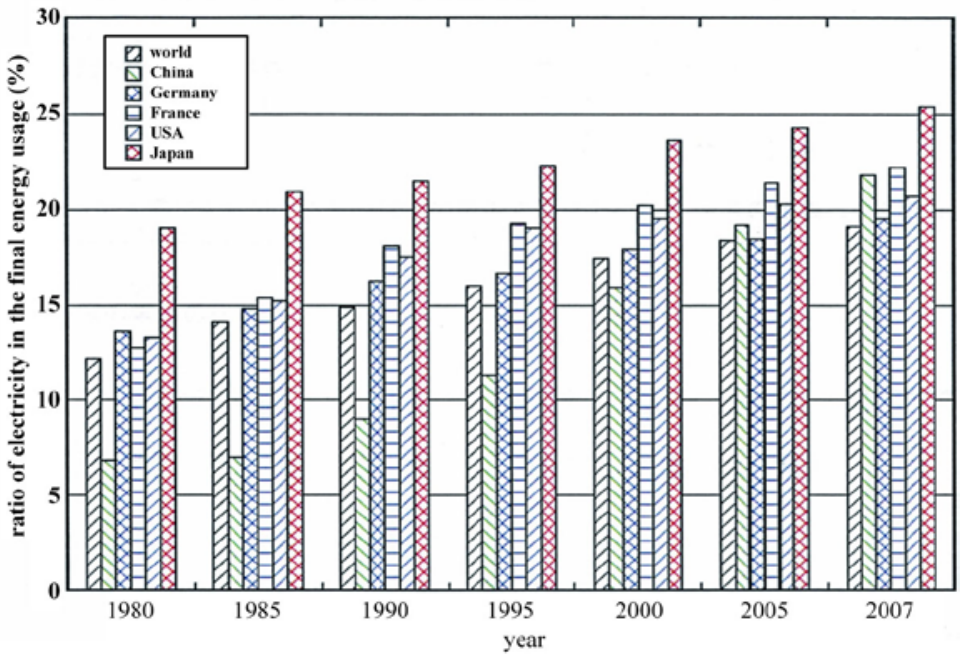

Figure 7 Energy use through electricity from 1980 to 2007 [12]. and, more importantly, due to the fact that most new energy sources generate electricity directly and such important sectors as transport and heating will be mostly covered by it. It is anticipated that more than half of the final energy consumption will be through electricity by 2050 .

Because all countries in the world are trying to expand electricity through PV and wind power, some characteristics of electricity supply into the grid by intermittent sources are identified [13, 14].

Figure 8 shows a result of calculations carried out using data of Kyushu Electric Power Co. in Japan with 15 min resolution, where PV and wind (described in the abscissa of Fig. 8 as 'RE') are combined in such a manner as to minimize the need for backup energies ('optimal mix') necessary to provide electricity during unfavourable natural periods. It is to be noted that the backup energy shown in black in the figure indicates annual electricity supplied from other sources than 'RE' (e.g., PV and wind). From the standpoint of the 'RE', it may be viewed as working as 'backup', when the output from 'RE' is not sufficient to cover the energy required from the load.

One recognises a strong increase of surplus energy and maximum grid power (dashed curve) as soon as the ratio of REs against load grows above 40 . If the annual electricity consumption is supplied by REs, the surplus energy becomes about 27 TWh and the same amount has to be provided by the back-up system. This corresponds to about $1 / 3$ of the annual load of Kyushu of 95 TWh. Beyond the $40 \%$ share, the technological problems in handling the excess power rise and an

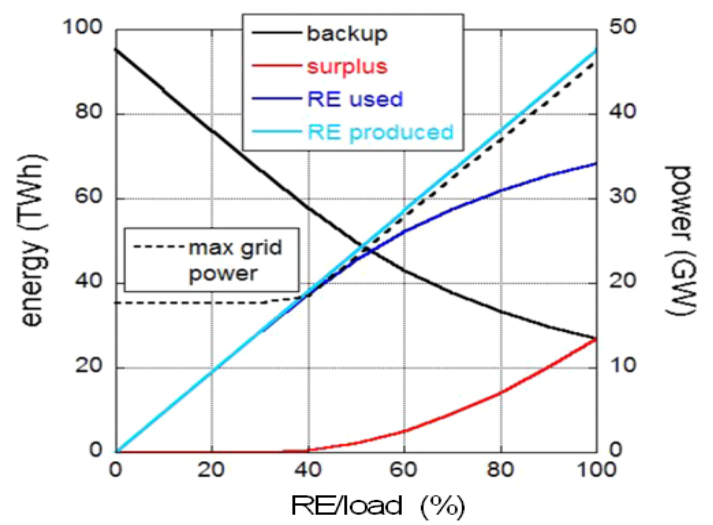

Figure 8 Energies of backup, surplus, RE used, and RE produced (left-hand ordinate), and max grid power (right-hand ordinate) for Kyushu [14]. 
economic operation of the back-up system is severely questioned. Figure 8 clearly illustrates the importance of electricity storage, in order for REs to be fully integrated into an electricity supply grid.

Figure 9 shows the decrease of backup energies as storage capacities for Kyushu are increased, indicating the necessity of about 5.3 TWh (about $5 \%$ of the annual load) for avoiding any backup power sources at all. However, this is about 250 times the present capacity of pumped storages of Kyushu Electric Power Co. (about $20 \mathrm{GWh}$ ). Figure 9 also shows that the backup energy can be substantially lowered already with a storage capacity of 0.5 TWh (about 25 times the present pumped storage capacity).

These findings for Japan are almost similar with

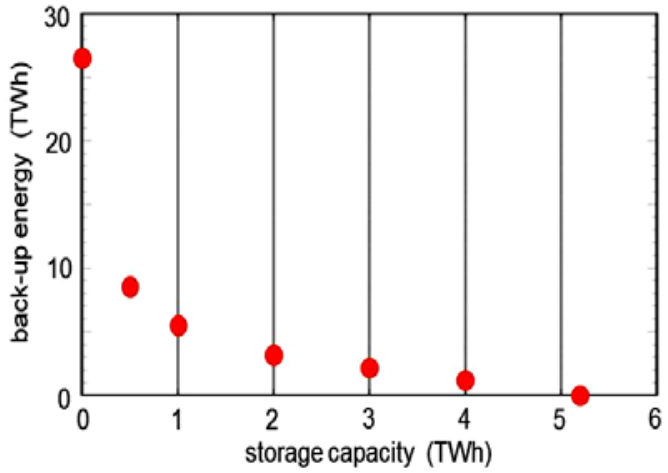

Figure 9 Decrease of backup energy as the storage capacity is increased for Kyushu [14]. those for Germany and other European countries [8,13], indicating that these characteristics of electricity are generic and introduced by the intermittencies of PV and wind, and do not much depend on national weather and demand conditions.

The authors believe that large power plants will continue to play an important role in the electricity generation, transmission/distribution and usage in a foreseeable future, in particular in industrial sectors, where roughly half of the overall energy consumption is and will continue to be concentrated in any industrialised country.

The only possible RE sources to be able to play such a role are wind and PV, as discussed above. Although some energy consumption in household, offices/services and transportation may be supplied by PV on rooftops, a major part will have to be supplied by electricity generated at large PV and wind parks specifically considering ongoing urbanisation.

Smart grids, decentralised dispatching, and integration of REs into the distribution sector will be very effective in efficient use of electricity, contributing to energy saving. However, the overall structure of electricity generation, transmission/distribution and usage say in 2050 will be, by the authors' opinion, not very much different from the present situation, except for the large proportion of primary energy sources from fossil fuels being replaced by other sources (REs including bio-mass, supplemented by inherently safe nuclear energy, if indeed needed and accepted by society).

\section{Long-range energy strategies for Japan and the world}

In order to chart long-range energy strategies, there may be approaches from two different directions, namely (i) developments of completely new energy sources not available at present, which require long-time and concerted worldwide efforts to bring them into realization, and (ii) developments of new energy storage systems to fully exploit the potential of PV and wind power allowing the storage and delayed use of surplus electricity.

\subsection{New energy sources}

Although there have been numerous methods to supply energies for human use which have not been utilized until now [3, 7], it is difficult to imagine novel technologies which can be scaled up to at a level of $1 \mathrm{kWh} /$ person/day (an average output of a few GW for a country having a 
population of 100 millions). However, two technologies might promise this quality for the second half of this century, namely solar fuels and thermonuclear fusion. In the following, these technologies are briefly commented.

\subsubsection{Solar fuels}

Usual biofuel processes relying on photosynthesis, through either harvested organic materials, such as sugar beets and rapeseeds, or carbohydrates, have very low conversion efficiencies from sunlight to energy (less than 1\%), so that these may be unlikely to become viable energy sources for industrialized countries [3, 7]. On the other hand, there may be a potential of solar fuels by bypassing chemical/thermal processes inevitable in the above-mentioned organic materials or carbohydrates. In particular, techniques of genetic modification to enhance hydrogen production may open up a new horizon for energy research, by aiming at a theoretical conversion efficiency from sunlight to energy of a few tens of percent [7], almost similar to that of PV.

\subsubsection{Thermonuclear fusion}

ITER (International Thermonuclear Experimental Reactor), the first but still experimental fusion reactor project, is being built in France in the frame of an international collaboration of Japan, EU, USA, Russia, China, South-Korea and India [15]. The device is planned to start operation at the beginning of the 2020s. If this project will turn out to be successful as well as the accompanying material development project, the Demonstration Power plant (DEMO) will be built around 2045. When these projects are successful, a Commercial Power Plant will follow and will start to supply electricity to the grids around 2060. This is illustrated in Fig. 4 in the latter half of this century with a rather optimistic expansion beyond 2060 with an increase of about $1.5 \mathrm{kWh} /$ person/day per year for Japan, which corresponds to 7 fusion reactors/year having an electricity output of $1 \mathrm{GW}$ each for the then Japanese population of about 100 million people. If successful, the introduction of fusion energy may change the energy scene for the whole world in the second half of this century.

However, if fusion is to play a role for society, its development needs to be much speeded up, and hopefully to start supplying electricity well before 2040 as is evident from Fig. 4 to fill up its white blank area. Most fusion researchers may say that realisation of fusion energy within 30 years from now is unrealistic. However, this is based on a rather low global budget for fusion research of about 3 billion Euro per year (in comparison the global budgets for PV and for wind energy are in the order of 100-150 and 500 billion Euro per year, respectively). It is possible to speed up fusion research and bring it to fruition at an earlier time scale if the fusion research budget is increased from the present level, similar to the man-on-the-moon project in the sixties. Bearing in mind the present situation for mankind, which doesn't leave us with many options, one must pursue thermonuclear fusion and get it to work. One may remember the famous phrase by L Artsimovich, a fusion pioneer of the former Soviet Union, "Fusion will be there when society needs it” [16]. It is the authors' belief that this endeavour is worth pushing forward as the biggest project in the $21^{\text {st }}$ century with all possible resources to make this source finally available.

\subsection{Energy storage systems}

In order to meet the target of a few \% of the total annual load as storage capacity, as discussed in Sec. 4.3, Japan and the world need completely different technologies from the proven pumped hydro storage. Two examples which may prove promising are discussed. 


\subsubsection{Batteries}

Batteries are an established technology widely used to store electrical energy for various purposes. However, their capacities are very low as compared with those required for electricity storage of intermittent energy sources as described in Sec. 4.3. We can easily understand the size of the problem by analysing a specific proposal [3] - to use car batteries to store energy. The idea is to use two batteries for one electric-vehicle so that one is on board while the other one is placed at a charging station, where it is used for controlling electricity as well as charging when the load is low (thus electricity is cheap). For example, Japan annually consumes about $1.1 \times 10^{12} \mathrm{kWh}$, and $5 \%$ of it - the level of a seasonal storage - is $5.5 \times 10^{10} \mathrm{kWh}$. A battery of a present electric vehicle has a capacity of about $40 \mathrm{kWh}$, and the number of cars for the above value of $5.5 \times 10^{10} \mathrm{kWh}$ is $1.4 \times 10^{9}$. Presently, there are about $8.0 \times 10^{7}$ cars in Japan, implying that 20-times the present number of cars, together with all cars to be converted to be electricitydriven, is required. As described at the end of Section 4.1 together with Fig. 9, the backup energy can be substantially lowered at the storage capacity of $0.5 \%$ of the annual load, which corresponds to about a weekly storage [8]. Even then, the necessary number of electric cars is twice the present number in Japan. A daily storage is about $0.13 \%$ of the annual load [8], requiring about half the present number of cars in Japan. However, the still needed backup energy has to be increased accordingly.

Energy use through electricity is now only one quarter of the national energy consumption, and if all energy use will become through electricity supplied by PV and wind power by around 2050, as assumed here, the necessary number of cars has to accordingly increase. Here, it is to be noted that no attention has been paid to the constraint of limited supplies of materials necessary for producing such a vast amount of batteries.

As evident from these numbers, there must be very large breakthroughs in order for this approach to come into fruition.

\subsubsection{Hydrogen}

It has been known for a long time that hydrogen is a useful form of storing energy, from which one can easily obtain heat by simply burning it in air. Subsequently, a concept of fuel cells was invented, in which hydrogen reacts with oxygen under the presence of catalysts to yield electricity. Thus, it is only a matter of economically realising the infrastructure to exploit its potential as a means of energy storage, namely efficient production, storage and distribution of hydrogen. In recent years, there has been much development work in all these areas, and the year 2014 was coined as "The zero-th year of hydrogen" in Japan, partly by commercialization of fuel-cell driven cars named "Mirai" (literally "Future") from Toyota Motor Co. Also, Toshiba has started a field-test to store hydrogen produced from wind electricity in Goto-island, off Kyushu, which will be subsequently used for domestic uses on the island [17].

In order to meet the requirement of a storage capacity to facilitate $100 \%$ of energy supply by PV and wind power in the latter half of this century, many breakthroughs in all areas of hydrogen technology will have to be made. In this respect, it is noteworthy to point out recent research/development activities in the world, e.g., Energie Agentur.-NRW in Germany [18], Kyushu University in Japan [19], and National Renewable Research Laboratory in US [20].

If hydrogen will become a useful form of storing large amount of energy, also the so-called 'power to gas' concept could be realized. Here, electricity from PV and wind will be first stored in the form of hydrogen, which will subsequently be converted back to electricity when needed. 
This scheme is, however, severely hampered by the transformation efficiencies even if fuel cell technology is used for the back-conversion. Because of the losses, the secondary electricity price might be unreasonably high in comparison with the one for primary electricity.

\section{Summary}

It has been the authors' intention firstly to describe the deep impact that the Fukushima nuclear accident has had on energy policies of Japan and the world, and then to try to chart possible energy strategies for Japan and the world for the future.

Regarding the Fukushima nuclear accident, it is sometimes referred to as one of the three turning points in modern Japanese history, with the other two being the Meiji Restoration of 1868 to open up its isolation after more than 200 years, and the consequences of the Second World War in 1945. It may well have been so for Japan, but the accident has had much wider general implication for energy policies around the world discrediting nuclear energy. On the other hand, since the industrial revolution starting in the $18^{\text {th }}$ century the 10 -fold population increase has caused about a 30-fold increase in energy consumption [21] which could have only be met by burning fossil fuels leading finally to global warming.

The example of Japan (see Fig. 4) highlights the complexity of replacing fossil fuels by other technologies while maintaining the level of a highly industrialized country with more than 100 million inhabitants. The short-range measures are (1) energy saving, (2) use of renewable energy, and (3) nuclear energy. As evidenced in Sec. 4, there seems to be no viable solution other than using more nuclear energy, until long-range developments described in Sec. 5 have been realised sometime in the second half of this century. With respect to nuclear energy, mankind faces a dilemma described by the Japanese saying, literally translated: "Either going forward or retreating backward leads to hell”. The way into the energy future is very unclear at present. In this case, only an insurance policy helps. For the energy supply for 10 bn people on earth by around 2050, the proper insurance is to intensify research and development now and without ideological blinders - to improve the efficiency of PV panels, to develop chemical storage techniques with appropriate process catalysts, to look for new forms of bio-reactors, to explore CCS even if it is not applied in high-density population areas and to develop the nuclear technologies such as fusion, inherently safe nuclear fission reactors and nuclear transmutation. This will be a costly programme; international cooperation will, however, allow sharing the burden.

\section{References}

[1] The present states of evacuation zones as of $5^{\text {th }}$ September 2015, Fukushima Prefecture (in Japanese), www.pref.fukushima.lg.jp/site/portal/list271-840.html.

[2] K. Muraoka, Energy situations in Japan before and after the Fukushima nuclear accident, A lecture at the Joint EPS-SIF International School on Energy, Villa Monastero, Varenna, Italy, 17-23 July, 2014, http://dx.doi.org/10.1051/epjconf/20159805003.

[3] D. MacKay, Sustainable energy - without the hot air, UIT, Cambridge, 2009. www. withouthotair.com/cft.pdf

[4] ESA NSIDC BIST 2012. 
[5] The fifth assessment report of the IPCC, 2014, https://www.ipcc.ch/report/ar5/

[6] Muraoka K., "Energies in the coming age for Japan”, Sangyo-Tosho Publishing, Tokyo, 2012 (a book published in Japanese).

[7] J. Hermans, Energy Survival Guide, Beta-Text Publishing, Amsterdam, 2006.

[8] F. Wagner, Electricity generation by intermittent sources, A lecture at the Joint EPS-SIF International School on Energy, Villa Monastero, Varenna, Italy, 17-23 July, 2014, http://dx.doi.org/10.1051/epjconf/20159804006.

[9] Pew Research Center, March 19, 2012.

[10] Reuters, Wednesday 13 April, 2012.

[11] S. Guo, China, the road to a major nuclear power country (Iwanami-Booklet, No. 843), 2012 (in Japanese).

[12] The Energy Conservation Center, Japan, Data of energy and economy 2009-2010 (in Japanese).

[13] F. Wagner, Electricity by intermittent sources: An analysis based on the German situation 2012, Eur. Phys. J. Plus 129 20, 2014.

[14] K. Muraoka, F. Wagner, and Y. Yamagata, Allowable limit of renewable energy into electricity systems, submitted for publication in J. Elect. Eng. Japan (in Japanese with an English abstract and figure/table captions).

[15] https://www.iter.org

[16] C. M. Braams and P. E. Stott, Nuclear Fusion, Institute of Physics Publishing, Bristol and Philadelphia, 2002.

[17] www.toshiba-smartcommunity.com/jp/smart-community/hydrogen

[18] www.fuelcell-nrw.de

[19] h2.kyushu-u.ac.jp

[20] www.nrel.gov/hydrogen/

[21] http://ourfiniteworld.com/2012/03/12/world-energy-consumption-since-1820-in-charts/ 